\title{
Quality of life and health care consultation in 13 to 18 year olds with abdominal pain predominant functional gastrointestinal diseases
}

Niranga Manjuri Devanarayana ${ }^{1 *}$, Shaman Rajindrajith² and Marc A Benninga ${ }^{3}$

\begin{abstract}
Background: Abdominal pain predominant functional gastrointestinal diseases (AP-FGD) are commonly seen in the paediatric age group. It has significant impact on daily activities of affected children. Main objective of this study was to assess the health related quality of life (HRQOL) in children with AP-FGD.

Method: This was a cross sectional survey conducted in children aged 13-18 years, in four randomly selected schools in Western province of Sri Lanka. Data was collected using a previously validated, self-administered questionnaire. It had questions on symptoms, HRQoL and health care consultation. AP-FGD were diagnosed using Rome III criteria.

Results: A total of 1850 questionnaires were included in the analysis [males 1000 (54.1\%), mean age 14.4 years and SD 1.3 years]. Of them, 305 (16.5\%) had AP-FGD [irritable bowel syndrome $=91(4.9 \%)$, functional dyspepsia $=11$ $(0.6 \%)$, abdominal migraine $=37(1.9 \%)$ and functional abdominal pain $=180(9.7 \%)$. Lower HRQoL scores for physical (83.6 vs. 91.4 in controls), social (85.0 vs. 92.7), emotional (73.6 vs. 82.7) and school (75.0 vs. 82.5) functioning domains, and lower overall scores (79.6 vs. 88.0) were seen in children with AP-FGD $(p<0.001)$. A weak but significant negative correlation was observed between HRQoL score and severity of abdominal pain $(r=-0.24$, $p<0.0001)$. Eighty five children (27.9\%) had sought healthcare for AP-FGD. Factors determining healthcare seeking were presence of abdominal bloating and vomiting $(p<0.05)$.
\end{abstract}

Conclusions: Children with AP-FGD have lower quality of life in all 4 domains. Those with severe symptoms have lower HRQoL. Approximately 28\% of children with AP-FGD seek healthcare for their symptoms.

Keywords: Pain abdomen, Child, Functional gastrointestinal disorder, Health care consultation, Quality of life, Teenage

\section{Background}

The World Health Organization defines health as "a state of complete physical, mental and social well-being and not merely the absence of disease or infirmity" [1]. Quality of life is a term used to refer to an individual's total well being. This includes all emotional, social and physical aspects of an individual's life. When the phrase is used in reference to medicine, it is called as "Health Related quality of Life (HRQoL).

\footnotetext{
* Correspondence: niranga1230@lycos.com

'Department of Physiology, Faculty of Medicine, University of Kelaniya,

Thalagolla Road, 11010 Ragama, Sri Lanka

Full list of author information is available at the end of the article
}

Abdominal pain predominant functional gastrointestinal diseases (AP-FGD) such as irritable bowel syndrome (IBS), functional abdominal pain (FAP), abdominal migraine $(\mathrm{AM})$ and functional dyspepsia (FD), are seen in approximately $12 \%$ of children and adolescents $[2,3]$. Even though not life threatening, AP-FGD are chronic, troublesome disorders which can have significant impact on life of the affected children. In the absence of biological measures of disease activity, HRQoL becomes an important objective measure of health status in children suffering from AP-FGD.

Several studies have so far assessed the quality of life in children and adolescents with AP-FGD and all of them have reported lower quality of life [4-9]. Most

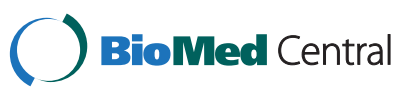


studies were conducted in young children and have assessed HRQoL using a parent report form and include children of younger age groups [4-7]. Studies reporting quality of life in teenagers with AP-FGD are rare $[8,9]$.

Abdominal pain is often an alarming symptom which leads to frequent healthcare consultation. Few studies conducted in children with abdominal pain, have reported healthcare consultation of 39 to $93 \%$ in affected children [10-14]. To date, no studies are available that have evaluated healthcare consultation in teenagers with AP-FGD.

HRQoL and healthcare seeking behaviours are likely to vary from country to country, community to community, depending on demographic and socio-cultural factors. HRQoL and healthcare consultation pattern in teenager are likely to be different from that of younger children. So far, no studies have assessed HRQoL and healthcare consultation in Sri Lankan teenagers with AP-FGD. This study was conducted with the main objective of assessing HRQoL and healthcare consultation in children aged 13-18 years in Sri Lanka and factors associated with them.

\section{Methods}

This was a cross sectional survey conducted in in the Western province of Sri Lanka.

\section{Data collection}

Western province of Sri Lanka has 1333 functioning government schools (similar to public schools). Of them, 427 are schools with students aged 13-18 years. From the list of these 427 schools available at the Provincial Education Office, four mixed gender schools were randomly selected by drawing lots. All children aged 13 to 18 years in these schools were invited to take part in the study.

Data on socio-demographic and family characteristics, symptoms, HRQoL and healthcare consultation were collected using a validated, self-administered questionnaire. Questionnaire was in native language (Sinhala). It consisted of 4 parts. First part contained questions on socio-demographic and family characteristics. Information regarding AP-FGD was collected using Rome III questionnaire for FGD (child report form for children above 10 years) (Part 2) [15]. This part of the questionnaire has been translated, validated and used for Sri Lankan children previously [2,3]. Part 3 was PedsQL, Pediatric Quality of Life Inventory 4.0 (Generic Core Scales) self report form for teens [16-18], which has been previously translated in to native language (Sinhala) and has undergone linguistic validation by Mapi Research Trust. The investigators have obtained permission to use this questionnaire for this study. Part 4 of the questionnaire contained questions regarding healthcare consultation. This part of the questionnaire has been developed by the investigators, pretested, and used previously in a school based study in Sri Lankan children [19].

This was an anonymous questionnaire, administered in examination setting, to ensure confidentiality and privacy. Research assistants were present and support was given during filling the questionnaire. Questionnaires were collected on the same day. Consent was obtained from school administration, teachers, parents and children themselves before administration of the questionnaire.

\section{Scales used}

The HRQoL inventory consisted of 23 items. It was used to assess the physical functioning (8 items), emotional functioning ( 5 items), social functioning ( 5 items), and school functioning (5 items) of the child. A 5-point response scale is used $(0=$ never a problem; $1=$ almost never a problem, $2=$ sometimes a problem, $3=$ often a problem, $4=$ almost always a problem) to record the responses. Items were reverse scored and linearly transformed to a zero to 100 scale $(0=100,1=75,2=50,3=25,4=0)$. Final HRQoL scores were computed out of 100, with higher scores indicating better HRQoL.

Symptom severity of abdominal pain, dyspepsia and bowel symptoms were recorded using a visual analogue scale $(100 \mathrm{~mm})$ rating between $0 \%$ to $100 \%$, where $0 \%$ is not having symptoms at all and $100 \%$ is having very severe symptoms.

\section{Definitions used}

AP-FGD; irritable bowel syndrome (IBS), functional dyspepsia (FD), abdominal migraine (AM) and functional abdominal pain (FAP), were diagnosed using Rome III criteria defined by Rasquin et al. in 2006 [20].

A child who has received treatment for abdominal pain during previous 3 months was considered as a healthcare consulter.

\section{Ethical approval}

Ethical approval was obtained from the Ethical Review Committee of the Sri Lanka College of Paediatricians.

\section{Statistical analysis}

The data were analyzed using Epilnfo (EpiInfo 6, version 6.04 (1996), Centres of Disease Control and Prevention, Atlanta, Georgia, USA and World Health Organization, Geneva, Switzerland). Total HRQoL scores were compared using unpaired $t$-test. Healthcare consultation between patients and controls were compared using $X^{2}$ test. Multiple logistic regression analysis was used to evaluate independent association between factors identified as significant in the univariable analysis. All correlations were done using Pearson correlation coefficient. $p<0.05$ was considered as significant. 


\section{Results}

A total of 1855 questionnaires were distributed and all of them were returned. Of them, 1850 (99.7\%) properly filled questionnaires were included in the analysis. There were 1000 (54.1\%) boys. Mean age of the participants was 14.4 years (SD 1.3 years).

A total of 305 (16.5\%) of children had AP-FGD. IBS was seen in $91(4.9 \%)$, FD was seen in $11(0.6 \%)$, AM was seen in 37 (1.9\%) and FAP was seen in 180 (9.7\%). Of them 13 had both IBS and AM and 1 had AM and FD. AP-FGD were significantly more prevalent in girls [175 (20.1\%) vs. $130(13.0 \%)$ in boys, $p<0.0001)]$. During analysis, 1545 children without AP-FGD were considered as controls.

\section{HRQoL in children with AP-FGD}

Table 1 shows the mean HRQoL scores in children with all four types of AP-FGD and controls. Children with AP-FGD had lower HRQoL scores than controls in all 4 domains (physical, emotional, social and school functioning). When HRQoL scores of children with different types of AP-FGD were analysed, children with IBS and AM had lower HRQoL scores for all four domains, compared to controls. Those with FAP had lower HRQoL scores only for physical and emotional functioning domains. There was no statistical difference between children with FD and controls (Table 1).

When HRQoL scores were compared between different AP-FGD types, lowest HRQoL scores were observed in children with AM $(78.6 \%)$ and IBS $(79.6 \%)(p<0.001$, compared to FAP and FD) (Table 1).

\section{Healthcare consultation in children with AP-FGD}

Table 2 shows the percentage of healthcare consultation according to AP-FGD type. Healthcare consultation in patients with AP-FGD was $27.9 \%$. In addition, $8.3 \%$ of controls have sought medical advice for abdominal pain due to other causes. When healthcare consultation between different AP-FGD types was compared, the highest rate was observed in children with AM (40.5\%).
Factors affecting HRQoL in children with AP-FGD

As depicted in Table 3, no significant differences were found in scores obtained for HRQoL according to sociodemographic and family characteristics in children with AP-FGD $(p>0.05)$.

HRQoL score had a weak but significant negative correlations with scores obtained for severity of abdominal pain $(\mathrm{r}=-0.24,95 \%$ confidence interval $(\mathrm{CI})-0.34$ to -0.13 , $p<0.0001)$, frequency of abdominal pain $(\mathrm{r}=-0.15$, $95 \%$ CI -0.26 to $-0.04, p=0.009$ ), severity of dyspepsia $(\mathrm{r}=-0.19,95 \% \mathrm{CI}-0.30$ to $-0.08, p=0.001)$ and severity of bowel symptoms $(\mathrm{r}=-0.15,95 \% \mathrm{CI}-0.25$ to 0.03 , $p=0.01)$.

\section{Factors determining healthcare consultation in children with AP-FGD}

The association between socio-demographic factors and healthcare consultation is shown in Table 3. Table 4 shows the association between symptom characteristics and healthcare consultation. Following multiple logistic regression analysis, abdominal bloating [adjusted odds ratio (OR) 2.1, $p=0.04$ ] and vomiting (adjusted OR 2.5, $p=0.02$ ) remained to be significantly associated with healthcare consultation.

In teenagers with AP-FGD, healthcare consulters had significantly higher scores for school functioning and physical functioning domains of HRQoL than nonconsulters (Figure 1).

\section{Discussion}

In this study, teenagers with AP-FGD had significantly lower HRQoL in all four domains; physical, emotional, social and school functioning. This lower HRQoL scores were significant in IBS, AM and FAP. Approximately 28\% of affected children seek healthcare for their symptoms. Factors independently associated with healthcare consultation were abdominal bloating and vomiting.

In this study, we found a slightly higher prevalence of AP-FGD than previously reported in Sri Lanka. In a previous study conducted in children age 12-16 years in a semi-urban school, AP-FGD were seen in 13.8\% [2].

Table 1 Health related quality of life (HRQoL) scores in children with abdominal predominant functional gastrointestinal diseases and controls

\begin{tabular}{|c|c|c|c|c|c|c|}
\hline Quality of life domains & $\begin{array}{l}\text { Irritable bowel } \\
\text { syndrome } \\
\text { Mean (SD) }\end{array}$ & $\begin{array}{l}\text { Functional } \\
\text { dyspepsia } \\
\text { Mean (SD) }\end{array}$ & $\begin{array}{l}\text { Abdominal } \\
\text { migraine } \\
\text { Mean (SD) }\end{array}$ & $\begin{array}{l}\text { Functional abdominal } \\
\text { pain } \\
\text { Mean (SD) }\end{array}$ & $\begin{array}{c}\text { AP-FGD } \\
\text { total } \\
\text { Mean (SD) }\end{array}$ & Mean (SD) \\
\hline Physical functioning (\%) & $84.7(15.1)^{* * * *}$ & $94.0(7.8)$ & $81.6(15.2)^{* * * *}$ & $89.1(12.1)^{* * *}$ & $87.9(13.4)^{* * * *}$ & $91.5(10.9)$ \\
\hline Emotional functioning (\%) & $70.1(21.2)^{* * * *}$ & $89.5(9.3)$ & $68.4(22.8)^{* * * *}$ & $77.8(19.7)^{* * * *}$ & $75.6(20.3)^{* * * *}$ & $83.4(17.0)$ \\
\hline Social functioning (\%) & $85.7(16.5)^{* * * *}$ & $95.0(9.2)$ & $86.3(15.6)^{* * * *}$ & $92.1(12.1)$ & $90.0(14.0)^{* * * *}$ & $92.7(11.6)$ \\
\hline School functioning (\%) & $74.1(18.7)^{* * * *}$ & $89.5(12.5)$ & $72.5(19.3)^{* * * *}$ & $79.9(16.6)^{*}$ & $78.0(18.0)^{* * * *}$ & $82.6(16.8)$ \\
\hline Total HRQoL score (\%) & $79.6(13.6)^{* * * *}$ & $92.3(5.6)$ & $78.6(12.7)^{* * * *}$ & $85.6(10.4)^{* *}$ & $83.8(11.8)^{* * * *}$ & $88.1(10.9)$ \\
\hline
\end{tabular}

AP-FGD $=$ abdominal pain predominant functional gastrointestinal diseases.

${ }^{*} p=0.04,{ }^{* *} p=0.006,{ }^{* * *} p=0.003,{ }^{* * * *} p<0.0001$ compared to controls, unpaired $t$-test. 
Table 2 Health care consultation in children with abdominal pain predominant functional gastrointestinal disorders

\begin{tabular}{lcc}
\hline & \multicolumn{2}{c}{ Health care consultation } \\
\cline { 2 - 3 } & $\begin{array}{c}\text { Consulters } \\
\boldsymbol{n}(\%)\end{array}$ & $\begin{array}{c}\text { Non-consulters } \\
\boldsymbol{n}(\%)\end{array}$ \\
\hline Irritable bowel syndrome & $27(29.7 \%)$ & $64(70.3 \%)$ \\
Functional dyspepsia & $4(36.4 \%)$ & $7(63.6 \%)$ \\
Abdominal migraine & $15(40.5 \%)$ & $22(59.5 \%)$ \\
Functional abdominal pain & $44(24.4 \%)$ & $136(75.6 \%)$ \\
Abdominal pain predominant & $85(27.9 \%)$ & $220(72.1 \%)$ \\
FGD total & & \\
Controls & $129(8.3 \%)$ & $1416(91.7 \%)$ \\
\hline
\end{tabular}

$\mathrm{FGD}=$ functional gastrointestinal disease.

Another study conducted in children aged 10-16 years in 8 schools of 4 provinces (out of 9 provinces of the country) has reported a prevalence of $12.5 \%$ [3]. A Colombian study conducted in a younger group of children (mean age 10 years) has reported AP-FGD in $10.8 \%$. Differences between age groups and socio-geographical factors may have accounted for these differences in prevalence [21]. Contrast to previous studies, commonest AP-FGD in our teenagers was FAP not IBS $[2,3]$. Prevalence of FD is lower in the current study than previously reported in Sri Lanka (3.5\%, $2.5 \%$ ) and Colombia (1.7\%) [2,3,21]. At the same time, we observed a significantly higher prevalence of FAP than in previous studies $(9.7 \%$ in current study vs. $3.0 \%, 4.5 \%$ and $2.7 \%$ in previous studies) $[2,3,21]$. The exact reason for this is not clear, but might be due to differences in age groups.

Very few studies have evaluated HRQoL in teenagers with AP-FGD. A recent school based study, conducted in 10 to 17 years old children, has reported significantly lower quality of school work in children with IBS, aerophagia and cyclic vomiting [8]. Another study conducted in high school children in Korea has also reported similar results [9]. Lower HRQoL has also been reported in younger children with AP-FGD. Varni et al. have evaluated HRQoL using a generic score scale in children 2 to 18 years with IBS and reported lower scores in all 4 domains [5]. In another study, children with FAP (mean age 11.2 years) had significantly lower HRQoL in physical and emotional domains compared to healthy controls [4]. In that study, HRQoL scores in children with FAP were similar to those with chronic organic diseases such as gastro-oesophageal reflux disease and inflammatory bowel disease. Several studies conducted in preschool children and adults with AP-FGD have also reported lower quality of life in affected children and adults [6,7,22-25].

We have compared HRQoL between four different types of AP-FGD. The lowest score was observed in those with AM. Prolonged periods of severe abdominal pain, and
Table 3 Quality of life scores and heath care consultation in children with abdominal pain predominant functional gastrointestinal disorders according to the socio-demongraphic and family characteristics

\begin{tabular}{|c|c|c|}
\hline Variable & $\begin{array}{c}\text { Health related } \\
\text { quality of life (\%) } \\
\text { Mean (SD) }\end{array}$ & $\begin{array}{c}\text { Health care } \\
\text { consultation } \\
n(\%)\end{array}$ \\
\hline \multicolumn{3}{|l|}{ Age } \\
\hline 13 years & $86.5(10.2)$ & $26(35.1 \%)$ \\
\hline 14 years & $84.5(12.7)$ & $18(22.8 \%)$ \\
\hline 15 years & $82.1(11.0)$ & $22(31.0 \%)$ \\
\hline 16 years & $81.9(11.9)$ & 7 (15.9\%) \\
\hline 17 years & $82.3(13.7)$ & $8(38.1 \%)$ \\
\hline 18 years & $81.6(11.8)$ & $4(25.0 \%)$ \\
\hline \multicolumn{3}{|l|}{ Sex } \\
\hline Male & $84.7(12.4)$ & $40(30.8 \%)$ \\
\hline Female & $83.1(11.4)$ & $45(25.7 \%)$ \\
\hline \multicolumn{3}{|l|}{ Family size } \\
\hline Only child & $86.2(11.2)$ & 11 (37.9\%) \\
\hline 2 children & $84.2(11.7)$ & $42(28.0 \%)$ \\
\hline 3 children & $83.3(11.5)$ & $27(27.6 \%)$ \\
\hline 4 children & $84.7(11.2)$ & $4(19.0 \%)$ \\
\hline 5 or more children & $67.4(17.4)$ & $1(14.3 \%)$ \\
\hline \multicolumn{3}{|l|}{ Birth order } \\
\hline $1 \mathrm{st}$ & $83.4(12.5)$ & 45 (30.2\%) \\
\hline 2nd & $84.5(10.9)$ & 31 (28.7\%) \\
\hline $3 r d$ & $83.7(9.4)$ & $5(14.3 \%)$ \\
\hline 4th & $85.1(12.9)$ & $3(30.0 \%)$ \\
\hline 5th or more & $68.1(24.3)$ & $1(33.3 \%)$ \\
\hline \multicolumn{3}{|l|}{ Father's social class } \\
\hline $\begin{array}{l}\text { Leading profession (e.g. doctor, } \\
\text { engineer) }\end{array}$ & $84.7(12.3)$ & $15(33.3 \%)$ \\
\hline $\begin{array}{l}\text { Lesser profession (e.g. nurse, } \\
\text { teacher) }\end{array}$ & $83.7(12.2)$ & $6(31.6 \%)$ \\
\hline Skilled non-manual (e.g. clerk) & $85.4(13.3)$ & $9(24.3 \%)$ \\
\hline $\begin{array}{l}\text { Skilled manual (e.g. mason, } \\
\text { carpenter) }\end{array}$ & $83.2(11.8)$ & $36(27.7 \%)$ \\
\hline Unskilled/unemployed & $82.4(10.8)$ & $11(28.2 \%)$ \\
\hline \multicolumn{3}{|l|}{ Maternal employment } \\
\hline $\begin{array}{l}\text { Leading profession (e.g. doctor, } \\
\text { engineer) }\end{array}$ & $83.6(10.6)$ & $2(25.0 \%)$ \\
\hline $\begin{array}{l}\text { Lesser profession (e.g. nurse, } \\
\text { teacher) }\end{array}$ & $82.8(15.8)$ & $4(28.6 \%)$ \\
\hline Skilled non-manual (e.g. clerk) & $84.0(11.2)$ & $2(25.0 \%)$ \\
\hline $\begin{array}{l}\text { Skilled manual (e.g. mason, } \\
\text { carpenter) }\end{array}$ & $85.2(11.3)$ & $8(22.9 \%)$ \\
\hline Unskilled/unemployed & $83.6(11.8)$ & $62(25.8 \%)$ \\
\hline
\end{tabular}


Table 4 Health care consultation in children with abdominal pain predominant functional gastrointestinal diseases according to symptoms

\begin{tabular}{|c|c|c|c|c|}
\hline & $\begin{array}{l}\text { Health care consulters } \\
\qquad n(\%)\end{array}$ & $\begin{array}{c}\text { Non consulters } \\
n(\%)\end{array}$ & $\begin{array}{c}\text { Odd ratio } \\
\text { (95\% Confidence Interval) }\end{array}$ & $P$ value* \\
\hline \multicolumn{5}{|c|}{ Frequency of abdominal pain } \\
\hline Once per week & $61(26.4 \%)$ & $170(73.6 \%)$ & $0.8(0.4-1.4)$ & 0.32 \\
\hline Several times per week & $20(32.8 \%)$ & $41(67.2 \%)$ & $1.3(0.7-2.6)$ & 0.34 \\
\hline Everyday & $4(30.8 \%)$ & $9(69.2 \%)$ & $1.2(0.3-4.3)$ & 0.81 \\
\hline \multicolumn{5}{|c|}{ Duration of a pain episodes } \\
\hline Less than 1 hour & $41(27.9 \%)$ & $106(72.1 \%)$ & $1.0(0.6-1.7)$ & 0.99 \\
\hline $1-2$ hours & $25(34.2 \%)$ & $48(65.8 \%)$ & $1.5(0.8-2.7)$ & 0.16 \\
\hline 3- 4 hours & $2(11.8 \%)$ & $15(88.2 \%)$ & $0.3(0.1-1.6)$ & 0.13 \\
\hline Most of the day & $17(25.0 \%)$ & $51(75.0 \%)$ & $0.8(0.4-1.6)$ & 0.55 \\
\hline \multicolumn{5}{|l|}{ Severity of pain } \\
\hline Mild & $14(26.4 \%)$ & $39(73.6 \%)$ & $0.9(0.4-1.9)$ & 0.80 \\
\hline Moderate & $43(25.4 \%)$ & $126(74.6 \%)$ & $0.8(0.5-1.3)$ & 0.29 \\
\hline Severe & $28(33.7 \%)$ & $55(66.3 \%)$ & $1.5(0.8-2.6)$ & 0.20 \\
\hline \multicolumn{5}{|l|}{ Location of pain } \\
\hline Upper abdomen & $5(38.5 \%)$ & $8(61.5 \%)$ & $1.7(0.5-5.8)$ & 0.38 \\
\hline Periumbilical & $58(33.1 \%)$ & $117(66.9 \%)$ & $1.9(1.1-3.3)$ & 0.02 \\
\hline Lower abdomen & $8(10.1 \%)$ & 71 (89.9\%) & $0.2(0.1-0.5)$ & $<0.0001$ \\
\hline Other & $14(36.8 \%)$ & $24(63.2 \%)$ & $1.6(0.7-3.5)$ & 0.19 \\
\hline \multicolumn{5}{|l|}{ Duration of the disease } \\
\hline 2 months & $26(32.9 \%)$ & $53(67.1 \%)$ & $1.4(0.8-2.5)$ & 0.25 \\
\hline 3 months & $18(30.5 \%)$ & $41(69.5 \%)$ & $1.2(0.6-2.3)$ & 0.61 \\
\hline 4-11 months & $12(31.6 \%)$ & $26(68.4 \%)$ & $1.2(0.6-2.7)$ & 0.58 \\
\hline More than 12 months & $29(22.5 \%)$ & $100(77.5 \%)$ & $0.6(0.4-1.1)$ & 0.07 \\
\hline \multicolumn{5}{|l|}{ Bloating } \\
\hline Yes & $18(43.9 \%)$ & $23(56.1 \%)$ & $2.3(1.1-4.8)$ & 0.01 \\
\hline No & $67(25.4 \%)$ & $197(74.6 \%)$ & & \\
\hline \multicolumn{5}{|l|}{ Early satiety } \\
\hline Yes & $14(31.1 \%)$ & $31(68.9 \%)$ & $1.2(0.6-2.5)$ & 0.60 \\
\hline No & $71(27.3 \%)$ & $189(72.7 \%)$ & & \\
\hline \multicolumn{5}{|l|}{ Loss of appetite } \\
\hline Yes & $33(30.3 \%)$ & $76(69.7 \%)$ & $1.2(0.7-2.1)$ & 0.48 \\
\hline No & $52(26.5 \%)$ & $144(73.5 \%)$ & & \\
\hline \multicolumn{5}{|l|}{ Nausea } \\
\hline Yes & $36(37.5 \%)$ & $60(62.5 \%)$ & $2.0(1.1-3.4)$ & 0.01 \\
\hline No & $49(26.7 \%)$ & $160(77.3 \%)$ & & \\
\hline \multicolumn{5}{|l|}{ Vomiting } \\
\hline Yes & $18(48.6 \%)$ & $19(51.4 \%)$ & $2.8(1.3-6.1)$ & 0.002 \\
\hline No & $67(25.0 \%)$ & $201(75.0 \%)$ & & \\
\hline \multicolumn{5}{|l|}{ Constipation } \\
\hline Yes & $29(37.2 \%)$ & 49 (62.8\%) & $1.8(1.0-3.2)$ & 0.03 \\
\hline No & 56 (24.7\%) & 171 (75.3\%) & & \\
\hline
\end{tabular}


Table 4 Health care consultation in children with abdominal pain predominant functional gastrointestinal diseases according to symptoms (Continued)

\begin{tabular}{|c|c|c|c|c|}
\hline \multicolumn{5}{|c|}{ Loose stools } \\
\hline Yes & $20(34.5 \%)$ & $38(65.5 \%)$ & $1.5(0.8-2.8)$ & 0.21 \\
\hline No & $65(26.3 \%)$ & $182(73.7 \%)$ & & \\
\hline \multicolumn{5}{|c|}{ Sleep disturbance } \\
\hline Yes & $32(31.1 \%)$ & $71(68.9 \%)$ & $1.3(0.7-2.2)$ & 0.37 \\
\hline No & $53(26.2 \%)$ & $149(73.8 \%)$ & & \\
\hline \multicolumn{5}{|c|}{ School absenteeism } \\
\hline Yes & $21(32.3 \%)$ & $44(67.7 \%)$ & $1.3(0.7-2.5)$ & 0.37 \\
\hline No & $64(26.7 \%)$ & $176(73.3 \%)$ & & \\
\hline \multicolumn{5}{|c|}{ Disturbance in daily activities } \\
\hline Yes & $43(30.7 \%)$ & 97 (69.3\%) & $1.3(0.8-2.2)$ & 0.31 \\
\hline No & $42(25.5 \%)$ & $123(74.5 \%)$ & & \\
\hline \multicolumn{5}{|c|}{ Headache } \\
\hline Yes & $38(29.7 \%)$ & $90(70.3 \%)$ & $1.2(0.7-2.0)$ & 0.31 \\
\hline No & $47(25.4 \%)$ & $130(74.6 \%)$ & & \\
\hline \multicolumn{5}{|c|}{ Photophobia } \\
\hline Yes & $16(31.4 \%)$ & 35 (68.6\%) & $1.2(0.6-2.5)$ & 0.54 \\
\hline No & $69(27.2 \%)$ & $185(72.8 \%)$ & & \\
\hline \multicolumn{5}{|l|}{ Pallor } \\
\hline Yes & $6(23.1 \%)$ & $20(76.9 \%)$ & $0.8(0.3-2.1)$ & 0.57 \\
\hline No & 79 (28.3\%) & 200 (71.7\%) & & \\
\hline
\end{tabular}

*Chi-square test.

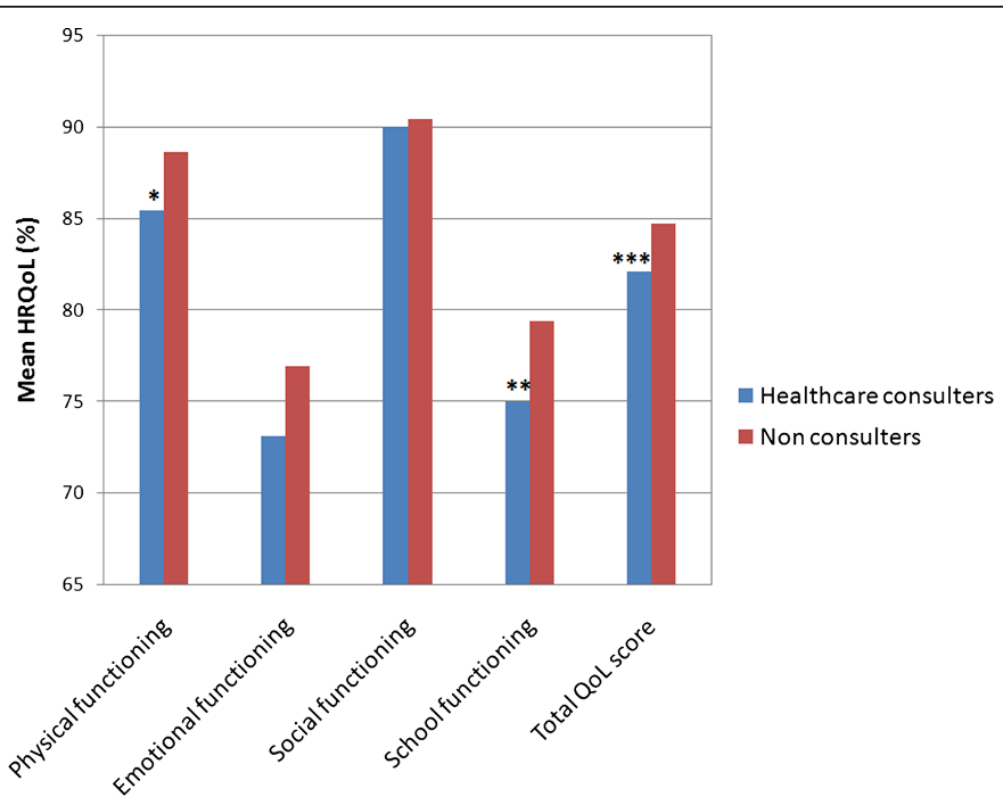

Figure 1 Association between HRQOL and healthcare consultation. ${ }^{*} p=0.03,{ }^{* *} p=0.048,{ }^{* * *} p=0.055$, comparison between healthcare consulters and non consulters (unpaired t-test). 
presence of other troublesome symptoms such as headache, may have contributed to this lower HRQoL. In addition, children with IBS had HRQoL significantly lower than that of those with FAP and FD. Presence of bowel symptoms, in addition to abdominal pain, may have contributed to this finding. A recent study assessing school related quality of life in children 10 to 17 years reported lowest scores in those with FAP (9.0) followed by FD (10.5), IBS (11.3) and AM (11.6) [8]. This is different from scores obtained for school functioning in our study (Table 1). The fact that the previous study has used different scale and scoring system to measure school related quality of life and the differences in ages of children recruited and sociocultural environments may have contributed to this difference.

We observed a weak, but significant inverse relationship between severity of symptoms (severity of abdominal pain, dyspepsia and bowel symptoms, and frequency of abdominal pain) and scores obtained for HRQoL. Similar to our results, Oostenbrink and co-workers have reported significant negative correlation between severity of abdominal pain and quality of life, in preschool children in the Netherlands [6]. Another study conducted in children with defecation disorders have found a similar correlation between HRQoL and abdominal pain and bloating [26]. Previous studies conducted in adult patients with functional gastrointestinal diseases have also reported lower HRQoL in patients with more severe symptoms [22]. There is a wide individual variation in perception of symptoms including pain. Sometimes patients with severe pain have fairly good quality of life while others with mild pain have poor quality of life. In our view, these individual variations may have contributed to the weak correlation observed in the current study between symptoms and HRQoL scores.

In this study, we did not find a relationship between HRQoL and age, gender, social class, maternal employment, family size and birth order. The relationship between socio-demographic and family characteristics and HRQoL has not been evaluated in paediatric patients with AP-FGD. However, contrary to our results, studies conducted in adult patients with functional gastrointestinal disorders have reported lower HRQoL in females compared to males [22].

In our study approximately $28 \%$ of affected children have sought medical advice for abdominal pain during previous 3 months. In addition, $8.3 \%$ of controls have also sought medical advice for abdominal pain due to other causes. There are no studies conducted in teenagers with AP-FGD on healthcare consultation. However, percentage of healthcare consultation in the current study is significantly lower than that reported in children with recurrent abdominal pain aged 5-15 years in Sri Lanka
(70\%) [12], and 9-15 years in Malaysia (45-48\%) [10,11]. Another study conducted in German children has shown healthcare consultation of $52 \%$ in children (3-10 years) and $39 \%$ in adolescents (11-17 years) [13]. Some studies have reported healthcare use as high as $93 \%$ in children aged 4 to 17 years with non-specific abdominal pain [14]. Age groups of children included in those previous studies are lower than the teenagers we recruited in the current study. Generally, parents are more aware of the gastrointestinal symptoms and bowel habits of younger children and more worried about such symptoms when their children are younger. Therefore, younger children are more likely to seek healthcare than older children. This may have contributed to the higher prevalence of healthcare consultation seen in previous studies.

We expected higher healthcare consultations in children from higher social class, small families and those with severe symptoms and disturbances in day to day life. However, none of the other symptoms or socio-demographic and family characteristics were associated with healthcare consultation. Sri Lanka has well established government hospitals and clinics where healthcare is provided free of charge. Average distance from a home to a healthcare facility is approximately $1.4 \mathrm{~km}$. This may have accounted for the lack of association between healthcare consultation and socio-economic factors. Previous studies conducted in children with abdominal pain have also failed to show an association between socioeconomic factors and healthcare consultation [10-12].

The symptoms independently associated with healthcare consultation in our study were abdominal bloating and vomiting. Similar to the current study, in the previous Sri Lankan study conducted in children aged 5 to 15 years with recurrent abdominal pain, the only symptom associated with healthcare consultation was vomiting [12]. In contrast to this, other previous studies conducted in younger children have shown significant associations between health care consultation and age of onset, severity, frequency and duration of pain episodes, school absenteeism, sleep interruption and disruption of normal activity $[10,11,27]$. It is parents who take the children to see a doctor. Unlike younger children, teenagers are reluctant to discuss their bodily symptoms with the parents. Some of the parents may not be aware of these symptoms in their children. That may be a reason for lack of association between healthcare consultation and some symptoms. However, a symptom like vomiting and bloating are visible to the parents and readily recognised. They are also alarming symptoms, especially in teenage girls in reproductive age. So those with bloating and vomiting are more likely to be taken to a doctor. In addition, due to variation in the perception of symptoms, the impact on the quality of life is more likely to influence healthcare consultation 
than the exact severity. In agreement with this, we found significantly lower scores for school functioning and physical functioning domains of HRQoL in healthcare consulters than in non consulters.

HRQoL is an indicator of the impact of a disease on the life of an individual and an indirect indicator of the disease severity. In this study we evaluated the impact of AP-FGD on physical, social, emotional and school functions of teenagers. Thirteen to eighteen years of life is a period with rapid physical, social and emotional development, and also a critical period in school education. Undesirable effects during this period are likely to have significant impact on development of the affected children and future social, emotional and financial stability. Long term and recurrent nature of the symptoms of AP-FGD and significantly decrease HRQoL of affected children are likely to have long term negative effects on their life. In addition, our results indicate that approximately quarter of Sri Lankan children with AP-FGD has sought medical advice for their symptoms during previous 3 months. Considering the high prevalence of this disease, AP-FGD in Sri Lankan teenagers are a significant burden on the already over-stretched healthcare system of the country. This needs to be taken in to consideration by healthcare personals, especially those looking after children with abdominal pain predominant functional gastrointestinal diseases. Prompt and effective management would not only decrease the suffering of the affected children, but also reduce the short term and long term impact of the disease on their life, their families, as well as the society.

The main strengths of the current study are inclusion of large number of teenagers and using standard and validated questionnaires for data collection. We believe that these have increased the reliability of our data. However, there were few limitations in this study. First, we did not investigate children to exclude organic causes for abdominal pain in the current questionnaire based survey. In a previous study we identified organic diseases in $10.9 \%$ of children with recurrent abdominal and nearly $89 \%$ had functional gastrointestinal diseases [28]. Similar results have been reported from other countries as well [29-31]. The organic diseases observed in the previous Sri Lankan study were urinary tract infection, gastroesophageal reflux disease, urinary calculi, antral gastritis, and intestinal amoebiasis [28]. Parasitic infestations such as giardiasis and amoebiasis have been considered to be possible mimickers of FGD; however, in that study, prevalence of these diseases was $1.8 \%$, similar to several previous studies conducted in Sri Lanka [32]. Secondly, because this is self-administered questionnaire there may be some degree of recall bias. Thirdly, we assess healthcare consultation for abdominal pain not specifically for AP-FGD.

\section{Conclusions}

This study has assessed HRQoL and healthcare consultation in Sri Lankan teenagers aged 13 to 18 years with abdominal pain predominant functional gastrointestinal diseases. Children with AP-FGD have significantly lower HRQoL scores for physical, emotional, social and school functioning. Approximately $28 \%$ of affected children have sought medical advice for their symptoms during previous 3 months. The main symptoms associated with healthcare consultation were abdominal bloating and vomiting. The health-related quality of life was an important determinant of healthcare consultation, more than the severity of individual symptoms.

\section{Abbreviations}

AM: Abdominal migraine; AP-FGD: Abdominal pain predominant functional gastrointestinal disorders; FAP: Functional abdominal pain; FD: Functional dyspepsia; FGD: Functional gastrointestinal disorders; HRQoL: Health related quality of life; IBS: Irritable bowel syndrome.

\section{Competing interest}

None of the authors have any potential competing interest.

\section{Authors' contribution}

ND and SR developed the initial concept and collected the data. ND analysed and wrote the initial version of the manuscript. MAB and SR contributed to the final version of the manuscript by critically analysing it. All authors are in agreement with the content of the article. All authors read and approved the final manuscript.

\section{Funding}

Conducted with personal funds of the corresponding author.

\section{Author details}

'Department of Physiology, Faculty of Medicine, University of Kelaniya, Thalagolla Road, 11010 Ragama, Sri Lanka. ${ }^{2}$ Department of Paediatrics, Faculty of Medicine, University of Kelaniya, Thalagolla Road, 11010 Ragama, Sri Lanka. ${ }^{3}$ Department of Pediatric Gastroenterology and Nutrition, Emma Children's Hospital, Academic Medical Centre, Amsterdam, The Netherlands.

Received: 22 June 2013 Accepted: 15 August 2014

Published: 21 August 2014

\section{References}

1. World Health Organization: Handbook of basic documents. Geneva: World Health Organization; 1949.

2. Devanarayana NM, Adhikari C, Pannala W, Rajindrajith S: Prevalence of functional gastrointestinal diseases in a cohort of Sri Lankan adolescents: comparison between Rome II and Rome III criteria. J Trop Pediatr 2011, 57:34-39.

3. Devanarayana NM, Mettananda S, Liyanarachchi C, Nanayakkara N, Mendis N, Perera N, Rajindrajith S: Abdominal pain-predominant functional gastrointestinal diseases in children and adolescents: prevalence, symptomatology, and association with emotional stress. J Pediatr Gastroenterol Nutr 2011, 53:659-665.

4. Youssef NN, Murphy TG, Langseder AL, Rosh JR: Quality of life for children with functional abdominal pain: a comparison study of patients' and parents' perceptions. Pediatrics 2006, 117:54-59.

5. Varni JW, Lane MM, Burwinkle TM, Fontaine EN, Youssef NN, Schwimmer JB, Pardee PE, Pohl JF, Easley DJ: Health-related quality of life in pediatric patients with irritable bowel syndrome: a comparative analysis. J Dev Behav Pediatr 2006, 27:451-458.

6. Oostenbrink R, Jongman H, Landgraf JM, Raat H, Moll HA: Functional abdominal complaints in pre-school children: parental reports of health-related quality of life. Qual Life Res 2010, 19:363-369.

7. Spuijbroek AT, Oostenbrink R, Landgraf JM, Rietveld E, de Goede-Bolder A, van Beeck EF, van Baar M, Raat H, Moll HA: Health-related quality of life in 
preschool children in five health conditions. Qual Life Res 2011, 20:779-786.

8. Sagawa T, Okamura S, Kakizaki S, Zhang Y, Morita K, Mori M: Functional gastrointestinal disorders in adolescents and quality of school life. J Gastroenterol Hepatol 2013, 28:285-290.

9. Park H, Lim S: Frequency of irritable bowel syndrome, entrance examination-related stress, mental health, and quality of life in high school students. Gastroenterol Nurs 2011, 34:450-458.

10. Boey CC, Goh KL: Recurrent abdominal pain and consulting behaviour among children in a rural community in Malaysia. Dig Liver Dis 2001, 33:140-144

11. Boey CC, Goh KL: Predictors of health-care consultation for recurrent abdominal pain among urban schoolchildren in Malaysia. J Gastroenterol Hepatol 2001, 16:154-159.

12. Devanarayana NM, de Silva DG, de Silva HJ: Recurrent abdominal pain syndrome in a cohort of Sri Lankan children and adolescents. J Trop Pediatr 2008, 54:178-183

13. Schwille IJ, Giel KE, Ellert U, Zipfel S, Enck P: A community-based survey of abdominal pain prevalence, characteristics, and health care use among children. Clin Gastroenterol Hepatol 2009, 7:1062-1068.

14. Gieteling MJ, Lisman-van Leeuwen Y, van der Wouden JC, Schellevis FG, Berger MY: Childhood nonspecific abdominal pain in family practice: incidence, associated factors, and management. Ann Fam Med 2011, 9:337-343.

15. Drossman DA: Rome III : the functional gastrointestinal disorders. 3rd edition. McLean, Va: Degnon Associates; 2006.

16. Varni JW, Seid M, Kurtin PS: PedsQL 4.0: reliability and validity of the Pediatric Quality of Life Inventory version 4.0 generic core scales in healthy and patient populations. Med Care 2001, 39:800-812.

17. Varni JW, Burwinkle TM, Seid M, Skarr D: The PedsQL 4.0 as a pediatric population health measure: feasibility, reliability, and validity. Ambul Pediatr 2003, 3:329-341.

18. Varni JW, Burwinkle TM, Seid M: The PedsQL 4.0 as a school population health measure: feasibility, reliability, and validity. Qual Life Res 2006, 15:203-215

19. Rajindrajith S, Devanarayana NM, Benninga MA: Children and adolescents with chronic constipation: how many seek healthcare and what determines it? J Trop Pediatr 2012, 58:280-285.

20. Rasquin A, Di Lorenzo C, Forbes D, Guiraldes E, Hyams JS, Staiano A, Walker LS: Childhood functional gastrointestinal disorders: child/adolescent. Gastroenterology 2006, 130:1527-1537.

21. Saps M, Nichols-Vinueza DX, Rosen JM, Velasco-Benitez CA: Prevalence of functional gastrointestinal disorders in colombian school children. J Pediatr 2014, 164:542-545 e541.

22. Simren M, Svedlund J, Posserud I, Bjornsson ES, Abrahamsson H: Health-related quality of life in patients attending a gastroenterology outpatient clinic: functional disorders versus organic diseases. Clin Gastroenterol Hepatol 2006, 4:187-195.

23. Lee V, Guthrie E, Robinson A, Kennedy A, Tomenson B, Rogers A, Thompson $D$ : Functional bowel disorders in primary care: factors associated with health-related quality of life and doctor consultation. J Psychosom Res 2008, 64:129-138.

24. Icks A, Haastert B, Enck P, Rathmann W, Giani G: Health-related quality of life in subjects with functional bowel disorders in Germany. Z Gastroenterol 2002, 40:863-867.

25. ten Berg MJ, Goettsch WG, van den Boom G, Smout AJ, Herings RM: Quality of life of patients with irritable bowel syndrome is low compared to others with chronic diseases. Eur J Gastroenterol Hepatol 2006, 18:475-481

26. Walter $\mathrm{S}$, Hjortswang $\mathrm{H}$, Holmgren $\mathrm{K}$, Hallbook O: Association between bowel symptoms, symptom severity, and quality of life in Swedish patients with fecal incontinence. Scand J Gastroenterol 2011, 46:6-12.

27. Hyams JS, Burke G, Davis PM, Rzepski B, Andrulonis PA: Abdominal pain and irritable bowel syndrome in adolescents: a community-based study. J Pediatr 1996, 129:220-226.

28. Devanarayana NM, de Silva DG, de Silva HJ: Aetiology of recurrent abdominal pain in a cohort of Sri Lankan children. $J$ Paediatr Child Health 2008, 44:195-200

29. Apley J, Naish N: Recurrent abdominal pains: a field survey of 1,000 school children. Arch Dis Child 1958, 33:165-170.
30. Dutta S, Mehta M, Verma IC: Recurrent abdominal pain in Indian children and its relation with school and family environment. Indian Pediatr 1999 36:917-920

31. Alfven G: One hundred cases of recurrent abdominal pain in children: diagnostic procedures and criteria for a psychosomatic diagnosis. Acta Paediatr 2003, 92:43-49.

32. de Silva NR, de Silva HJ, Jayapani VP: Intestinal parasitoses in the Kandy area, Sri Lanka. Southeast Asian J Trop Med Public Health 1994, 25:469-473.

doi:10.1186/1471-230X-14-150

Cite this article as: Devanarayana et al:: Quality of life and health care consultation in 13 to 18 year olds with abdominal pain predominant functional gastrointestinal diseases. BMC Gastroenterology 2014 14:150.

\section{Submit your next manuscript to BioMed Central and take full advantage of:}

- Convenient online submission

- Thorough peer review

- No space constraints or color figure charges

- Immediate publication on acceptance

- Inclusion in PubMed, CAS, Scopus and Google Scholar

- Research which is freely available for redistribution 